\title{
Strontium-Substituted Apatite Coating Grown on Ti6Al4V Substrate Through Biomimetic Synthesis
}

\author{
A. L. Oliveira, ${ }^{1,2}$ R. L. Reis, ${ }^{2}$ P. Li ${ }^{1}$ \\ ${ }^{1}$ DePuy Orthopaedics, Inc., 700 Orthopaedics Drive, Warsaw, Indiana 46581 \\ 2 3B's Research Group-Biomaterials, Biodegradables and Biomimetics, University of Minho, \\ Campus Gualtar, 4710-057 Braga, Portugal
}

Received 6 February 2006; revised 2 January 2007; accepted 5 January 2007

Published online 23 April 2007 in Wiley InterScience (www.interscience.wiley.com). DOI: 10.1002/jbm.b.30791

\begin{abstract}
During the last few years Strontium has been shown to have beneficial effects when incorporated at certain doses in bone by stimulating bone formation. It is believed that its presence locally at the interface between an implant and bone will enhance osteointegration and therefore, ensure the longevity of a joint prosthesis. In this study we explore the possibility of incorporating $\mathrm{Sr}$ into nano-apatite coatings prepared by a solution-derived process according to an established biomimetic methodology for coating titanium based implants. The way this element is incorporated in the apatite structure and its effects on the stereochemistry and morphology of the resulting apatite layers was investigated, as well as its effect in the mineralization kinetics. By using the present methodology it was possible to incorporate increasing amounts of $\mathrm{Sr}$ in the apatite layers. $\mathrm{Sr}$ was found to incorporate in the apatite layer through a substitution mechanism by replacing $\mathrm{Ca}$ in the apatite lattice. The presence of $\mathrm{Sr}$ in solution induced an inhibitory effect on mineralization, leading to a decrease in the thickness of the mineral layers. The obtained $\mathrm{Sr}$-substituted biomimetic coatings presented a bone-like structure similar to the one found in the human bone and therefore, are expected to enhance bone formation and osteointegration. (C) 2007 Wiley Periodicals, Inc. J Biomed Mater Res Part B: Appl Biomater 83B: 258-265, 2007
\end{abstract}

Keywords: apatite coating; biomimetic synthesis; calcium phosphate; titanium (alloys); strontium (ion substitution)

\section{INTRODUCTION}

Skeletal metabolism of Strontium (Sr) has been the subject of extensive study over the past several years. Because of its chemical and physical similarity to calcium, $\mathrm{Sr}$ is a natural bone-seeking trace element that accumulates in the skeleton. ${ }^{1}$ There is growing evidence that $\mathrm{Sr}$ influences bone remodeling by affecting both bone resorption and bone formation. ${ }^{2}$

Several studies ${ }^{3-5}$ indicate that $\mathrm{Sr}$ can affect the activity of cells in vitro, acting directly on osteoclasts to inhibit bone resorption. The presence of this trace element on the surface of bone at a level higher than that required for normal cell physiology, can be effective in blocking osteoclastic bone resorption without apparent cytotoxic effect on osteoblasts. ${ }^{4}$ Consistent with the in vitro data, available in vivo studies indicate that $\mathrm{Sr}$ has a metabolic effect on

Correspondence to: Dr. P. Li (e-mail: pli@dpyus.jnj.com) or Ana L. Oliveira (e-mail: analeite@dep.uminho.pt)

(C) 2007 Wiley Periodicals, Inc. bone. ${ }^{5-9}$ Positive effects were observed in different animal models namely those with predominant bone remodeling, like monkeys. ${ }^{10}$ The presence of $\mathrm{Sr}$ can enhance endosteal and trabecular bone formation without affecting bone mineralization and reducing bone resorption. These effects can directly influence the mechanical properties of bone, increasing the bone strength, while maintaining the bone physiological balance. These in vivo studies support the concept that $\mathrm{Sr}$ administration at a correctly defined dose can act on bone resorption, increasing bone formation, and reducing bone loss in animal models of osteopenia, suggesting that controlled doses of Sr may have potential benefits in the treatment of osteopenic disorders, like osteoporosis. ${ }^{8,11}$ In dental enamel, Sr was also found to stabilize the apatitic structure and induce higher resistance to degradation by bacterial acids. ${ }^{12,13}$

In the recent years clinical trials have been conducted on humans using a specific molecule, $\mathrm{Sr}$ ranelate, composed of an organic moiety that binds two stable $\mathrm{Sr}$ atoms for increasing $\mathrm{Sr}$ bioavailability. Low doses of $\mathrm{Sr}$ ranelate, when orally supplemented, were reported to increase vertebral bone calcification in osteoporotic patients. ${ }^{12,14-16} \mathrm{Im}$ - 
portant pharmacological and clinical data have clearly demonstrated that the presence of this Sr-based drug reduces the risk of vertebral ${ }^{17,18}$ and nonvertebral fractures ${ }^{19}$ in postmenopausal women with good tolerability in patients.

When orally supplemented, $\mathrm{Sr}$ can be retained in bone at a certain extent. A study in monkeys by Boivin et al. ${ }^{10}$ reported that when large doses of $\mathrm{Sr}$ were supplemented over a long period of time the calcium to $\mathrm{Sr}$ ratio reached a maximum of 10:1. This means that, low doses of $\mathrm{Sr}$ are required to elicit positive effects. In newly formed bone, $\mathrm{Sr}$ atoms are incorporated into the crystal by ionic substitution for calcium. ${ }^{9}$ Newly formed apatite crystals are more reactive and incorporate more $\mathrm{Sr}$ ions than the larger crystals, which grow more slowly. Complex effects of $\mathrm{Sr}$ on apatite crystals have been reported, ${ }^{1,11}$ such as a decrease in the apatite carbonate content and in crystal length. However, crystals containing Sr have demonstrated to be more stable and show more regular shapes. ${ }^{1,11}$ In this sense, $\mathrm{Sr}$ may also indirectly inhibit the resorption of the calcified matrix by stabilizing hydroxyapatite (HA) crystals.

When considering load-bearing cementless metallic implants, biological fixation is crucial for ensuring its longterm viability. Because of this osteoconductivity, hydroxyapatite ceramic has been used as a coating in joint reconstruction devices such as hip stems and acetabular cups. These coatings, commonly produced using a plasma spraying technique, ${ }^{20,21}$ have demonstrated direct bone apposition. ${ }^{22}$ However, concerns about delamination of the plasmasprayed HA coating and the potential for generating ceramic particles have discouraged its widespread acceptance. This fact has motivated a continuous search for effective ways of producing calcium phosphates more similar to those formed by the natural processes of bone mineralization, driving the attention over the last years to biomimetic methodologies. ${ }^{23-27}$ When coated with a layer similar to the natural mineral of bone, an orthopaedic implant besides exhibiting adequate mechanical properties to be used as bone replacement can also conduct bone formation and thereby, firmly integrate to bone. Following this idea, a solution-derived process was designed to produce a nano-apatite coating with a composition and structure equivalent to bone mineral. This coating is achieved by the immersion of titanium substrates in an aqueous solution comprising all major inorganic components present in the body, mainly, $\mathrm{HCO}_{3}^{-}, \mathrm{Ca}^{2+}, \mathrm{HPO}_{4}^{2-}$, and $\mathrm{Mg}^{2+}$ ions. ${ }^{28}$ The resulting apatite layers have demonstrated by in vivo studies to be capable of inducing bone formation and promoting direct bone apposition. ${ }^{28}$ Moreover, because of the physiologically related conditions for the formation of these coatings (in a solution with temperature, $\mathrm{pH}$ and inorganic composition close to human blood plasma) they present a high carrier potential at the surface of an implant, since, in this environment the biomolecules with therapeutic relevance can preserve their activity. The loading options are therefore numerous, going from protein growth factors ${ }^{29-31}$ to different therapeutic agents ${ }^{32}$ used in the treatment of bone related diseases.
Considering the beneficial effects of the presence of $\mathrm{Sr}$ in bone, reported in literature over the last years and herein shortly summarized, it is believed that its presence locally at the interface between the implant and bone via a calcium phosphate coating will stimulate bone formation, enhance osteointegration, and therefore ensure the longevity of a cementless implant. In this work we studied the possibility of incorporating different amounts of Sr onto the nano-apatite layers during the coating process. The effect on the coating properties like the morphology, chemistry and crystallinity was then evaluated.

\section{MATERIALS AND METHODS}

\section{Materials}

Titanium alloys are currently used in the manufacturing of joint implants. Twelve Ti-6A1-4V disks with a $16 \mathrm{~mm}$ in diameter and $2 \mathrm{~mm}$ in thickness were polished to have a reflective mirror-like finish, and another twelve disks were grit blasted using 20- $\mu \mathrm{m}$ alumina particles, per coating condition. A total of 48 polished and 48 grit blasted samples were used in the study. The distribution of the samples was as following: 3 samples/assay (all 3 used for TF-XRD followed by DR-FTIR and finally 2 for SEM) $\times 4$ [Sr] $\times 4$ time periods in solution: 24 and $50 \mathrm{~h}, 4$ and 7 days. In this paper we are reporting the results concerning the obtained coating after 7 days of coating. The specimens were ultrasonically cleaned first in a detergent solution, then in acetone, ethanol and finally in de-ionized water and then dried at $60^{\circ} \mathrm{C}$.

\section{Apatite Coating Formation}

A biomimetic nano-crystalline apatite coating was grown on the titanium specimens according to a procedure which was adapted from a previously developed process described by Li et al. ${ }^{28,33}$ An aqueous solution was prepared comprising all major inorganic ions present in the body, based in a simulated body fluid solution (SBF) initially proposed by Kokubo et al. ${ }^{27} \mathrm{CaCl}_{2}, \mathrm{NaCl}, \mathrm{KCl}, \mathrm{K}_{2} \mathrm{HPO}_{4}, \mathrm{MgCl}_{2}$, $\mathrm{NaSO}_{4}$, and $\mathrm{NaHCO}_{3}$ were dissolved in de-ionized $\mathrm{H}_{2} \mathrm{O}$ and the $\mathrm{pH}$ adjusted to neutral using tris(hydroxymethyl)aminomethane-hydrochloric acid. The solution was buffered at time 0 . The concentrations of $\mathrm{NaCl}, \mathrm{KCl}, \mathrm{NaHCO}_{3}, \mathrm{MgCl}_{2}$, and $\mathrm{NaSO}_{4}$ were designed to correspond to the nominal levels of human blood plasma, whereas the concentrations of $\mathrm{Ca}^{2+}$ and $\mathrm{HPO}_{4}^{2-}$ were 5.0 and $2.4 \mathrm{mM}$, respectively. Three other solutions were prepared based on the same procedure with the supplement of $0.5,1.0$, and $1.5 \mathrm{mM} \mathrm{SrCl}_{2}$ that results in the atomic ratio of $\mathrm{Ca}$ to $\mathrm{Sr}$ in solution of 10:1, 5:1, and 10:3, respectively. ${ }^{34}$ The lowest concentration of $\mathrm{Sr}$ is in the therapeutic range, when compared with the values found in human blood plasma in a study carried out in patients receiving a daily $\mathrm{Sr}$ supplement. ${ }^{12}$ Concerning the ideal concentration of $\mathrm{Sr}$ in bone a consensus has not been reached. In the literature several studies report different 


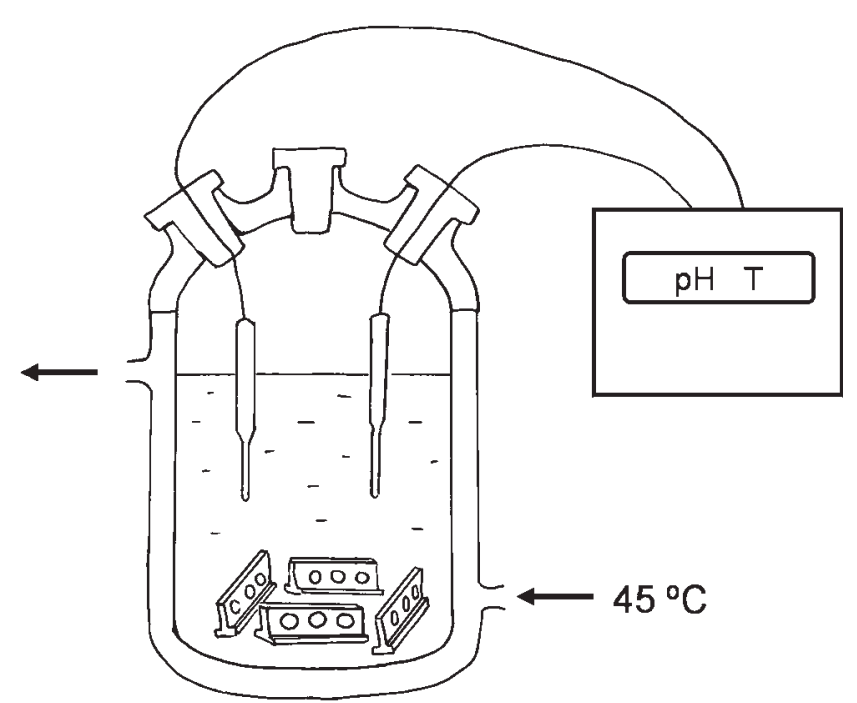

Figure 1. Schematic drawing of the coating experiments in doublejacked glass reactors.

amounts of Sr found in bone $e^{1,6,12,35-38}$ which, however, cannot be directly compared, since they are referred to either different animal models or human subjects and different $\mathrm{Sr}$ therapies. Nevertheless in a review by Dahl et al. ${ }^{9} 10: 1$ is indicated as the theoretical maximum of the $\mathrm{Ca}$ to $\mathrm{Sr}$ ratio in bone, based on studies by Boivin et al. ${ }^{10}$ The as-prepared solutions were loaded in a $2 \mathrm{~L}$ double-jacketed glass reactor and the temperature was kept constant at $45^{\circ} \mathrm{C}$ using a water circulating controller. The samples were fixed in tailormade Teflon holders and placed in the reactors standing vertically. Such arrangement ensures that the coating formed on the surface of Ti disks will not result from sedimentation of precipitates in the solution. Figure 1 illustrates schematically the process. The disks were removed from solution after 7 days and cleaned with deionized water.

\section{Solution Analysis}

During the entire process the $\mathrm{pH}$ and temperature of the solutions were monitored (recorded every $10 \mathrm{~min}$ ) by a $\mathrm{pH} /$ ion meter ( $\mathrm{pH} /$ ion Meter 692, Metrohm, Switzerland). The change of $\mathrm{Ca}, \mathrm{P}$, and $\mathrm{Sr}$ concentrations in the coating solutions was followed by means of removing aliquots of $5 \mathrm{~mL}$ of solution every 10 to $12 \mathrm{~h}$. Atomic Absorption Spectroscopy (AA800, Perkin-Elmer, Norwalk, CT) was used to
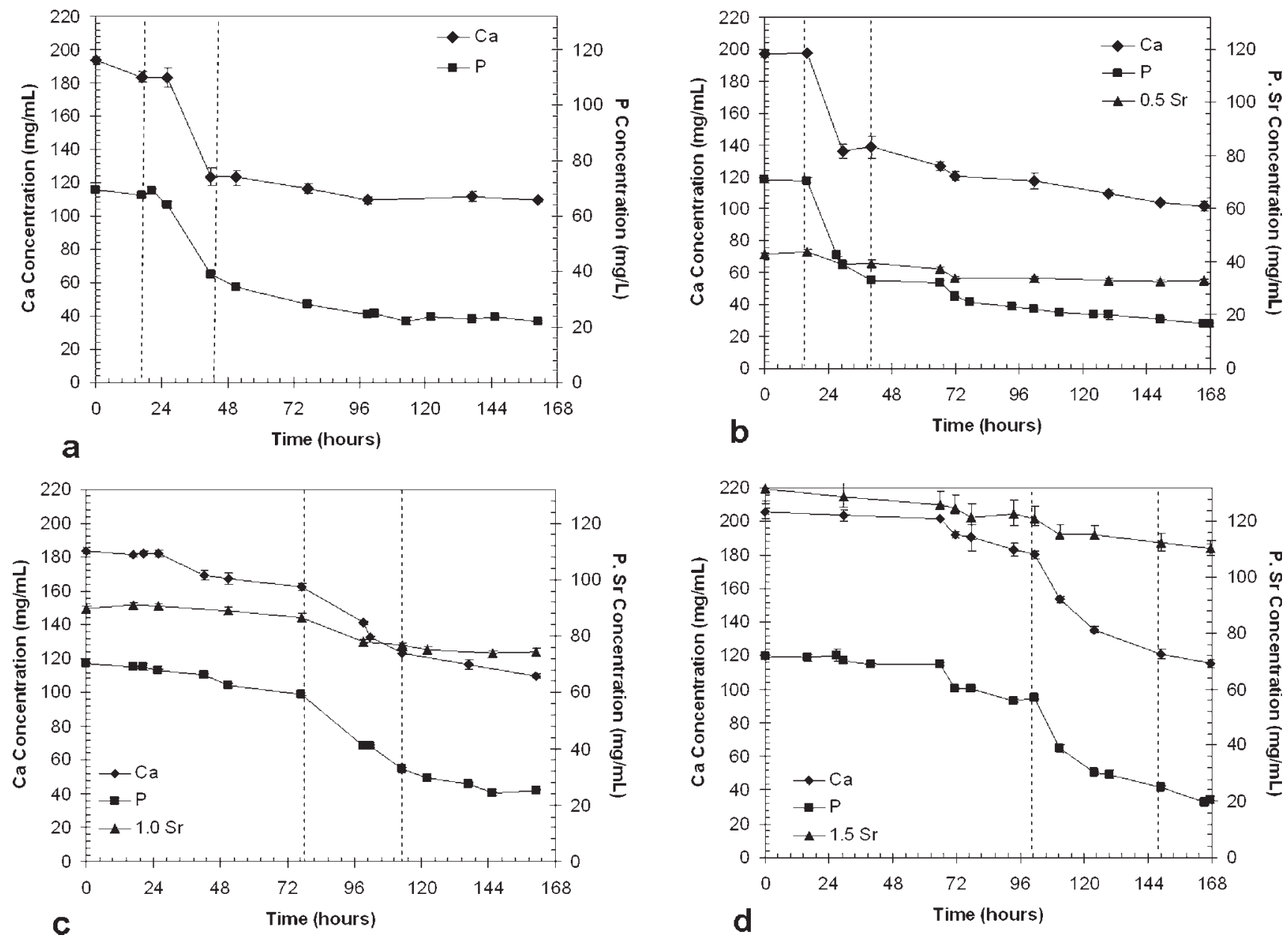

Figure 2. Evolution of $\mathrm{Ca}, \mathrm{P}$, and $\mathrm{Sr}$ composition of the different solutions during the coating process: (a) solution in the absence of $\mathrm{Sr}$ and with (b) 0.5 , (c) 1.0 , and (d) $1.5 \mathrm{mg} / \mathrm{mL}$ of Sr. 
quantify the amount of the $\mathrm{Ca}$ and $\mathrm{Sr}$ present. To eliminate the interference of phosphate in the measurement of calcium and $\mathrm{Sr}, 0.1 \mathrm{~mL}$ of the sample solution was diluted in $5 \mathrm{~mL}$ of $0.625 \%$ wt of $\mathrm{LaCl}_{3}$ that acts as a release agent. The $\mathrm{P}$ concentration was analyzed by the "molybdenum blue" method ${ }^{39}$ using a UV-light spectrophotometer (Genesys 2, Spectronic Instruments). For both methods, for each time point 3 repetitions $/ 5$ replicates were analyzed, and the average values calculated.

\section{Characterization of the Apatite Coatings}

The formed apatite coatings were analyzed using Diffuse Reflectance Fourier Transform Infra-Red spectroscopy (DR-FTIR, Magna-IR 550, Nicolet, Madison, WI), ThinFilm X-Ray Diffractometry (TF-XRD, X'Pert PW3040, Philips, The Netherlands), and Scanning Electron Microscopy (SEM, S-3500N, Hitashi, Japan) linked with Energy-Dispersive Spectroscopy (EDS). Two samples were used for each assay. To perform the SEM analysis all the samples were coated with a thin film of carbon, by ion sputtering, prior to any observation. The crosssections of the coatings were also observed by SEM and its thickness calculated from the average of measurements performed in 5 equidistant points $(5 \mu \mathrm{m})$ along the cross-sections.

\section{RESULTS}

\section{Apatite Formation: The Solution Side}

The evolution of the $\mathrm{Ca}, \mathrm{P}$, and $\mathrm{Sr}$ composition in solution is presented in Figure 2.

When comparing the presented curves for each different solution, a concurrent drop in the concentration of $\mathrm{Ca}, \mathrm{P}$, and $\mathrm{Sr}$ is observed, indicating that these ions are being consumed from solution while the apatite coating is being formed. The solution without supplement of $\mathrm{SrCl}_{2}$ [Figure 2(a)], shows a drop in the concentration of $\mathrm{Ca}$ from $\sim 200$ to $123 \mathrm{mg} / \mathrm{L}$ and the $\mathrm{P}$ concentration from $\sim 70$ to $40 \mathrm{mg} /$ $\mathrm{mL}$ between the first 24 and $48 \mathrm{~h}$. When $0.5 \mathrm{mM}$ of $\mathrm{Sr}$ is added to the solution [Figure 2(b)] the change of $\mathrm{Ca}$ and $\mathrm{P}$ concentrations is not considerably altered, suggesting that this amount of $\mathrm{Sr}$ does not affect significantly the driving forces for apatite formation. However, when $\mathrm{Sr}$ is raised to 1.0 [Figure 2(c)] and $1.5 \mathrm{mM}$ [Figure 2(d)] the $\mathrm{Ca}$ and $\mathrm{P}$ drop is delayed to $\sim 77$ and $90 \mathrm{~h}$ respectively. A retarding effect of $\mathrm{Sr}$ is, therefore, observed at these concentrations. This indicates an inhibitory effect of Sr. At the same time the concentration of this element in solution follows the same trend as of $\mathrm{Ca}$ and $\mathrm{P}$ concentration [Figure 2(a-c)]. This result indicates that the $\mathrm{Sr}$ ions can be incorporated in the structure of the apatite, possibly by competing with $\mathrm{Ca}$ ions for its substitution.
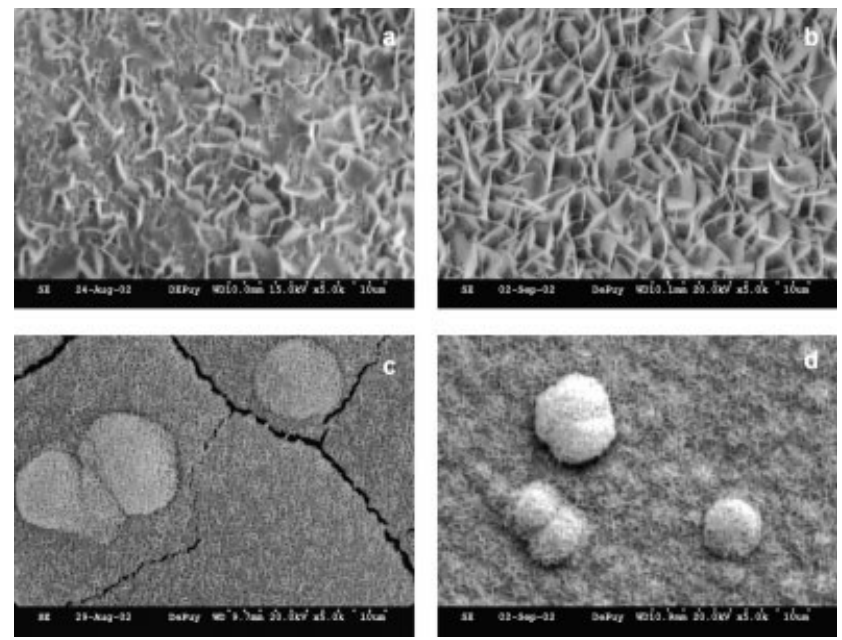

Figure 3. Morphologies of the apatite coatings formed after 7 days in the solutions containing: (a) 0 , (b) 0.5 , (c) 1.0 , and (d) $1.5 \mathrm{mM}$ of $\mathrm{Sr}$, concerning a polished sample.

\section{Apatite Formation: The Coating Side}

Figure 3 presents the morphologies of the apatite coatings formed after 7 days in the solution without $\mathrm{Sr}$ and with increasing concentrations of this element. The coating shows similar morphologies when formed on polished surfaces as compared with the coating on grit-blasted samples. Therefore, these micrographs concern the polished samples, being representative of the obtained morphologies for both cases.

After immersion in solution without the presence of $\mathrm{Sr}$ [Figure 3(a)], it was possible to observe a uniform coating on the surface of the samples, exhibiting a needle-like structure. When adding $0.5 \mathrm{~m} M$ of $\mathrm{Sr}$ to the solution the structure of crystals presented a more regular shape [Figure 3(b)]. These morphologies are typically found when octacalcium phosphate is present. ${ }^{40}$ When the amount of $\mathrm{Sr}$ in solution rises to 1.0 and $1.5 \mathrm{~m} M$ [Figure 3(c,d)] a remarkable change in the morphology is observed. The apatite crystals decrease from an approximate size of $\cong 2.5 \mu \mathrm{m}$ to the sub-micron level. This result indicates that the presence of $\mathrm{Sr}$ inhibits the apatite crystals from growing, leading to the formation of a nano-apatite structure.

Figure 4 presents SEM micrographs of the apatite layers' cross-sections after 7 days, for polished and grit-blasted samples as function of the amount of $\mathrm{Sr}$ in solution. The correspondent thickness evolution is plotted in Figure 5.

When comparing the apatite layers formed on the two types of surfaces studied, it is possible to observe that neither the morphology nor the thickness were influenced by the roughness of the $\mathrm{Ti}$ substrates [Figure 4(a-h)]. However, an increase in substrate roughness have improved adhesion of apatite coating to substrate because of a better mechanical interlocking with the apatite layer. ${ }^{25}$ When adding only $0.5 \mathrm{M} \mathrm{Sr}$ to the solution, a marked decrease in the thickness of the coating is observed.

Figure 6 shows a typical EDS spectrum obtained after 7 days for the coating produced in a solution containing 

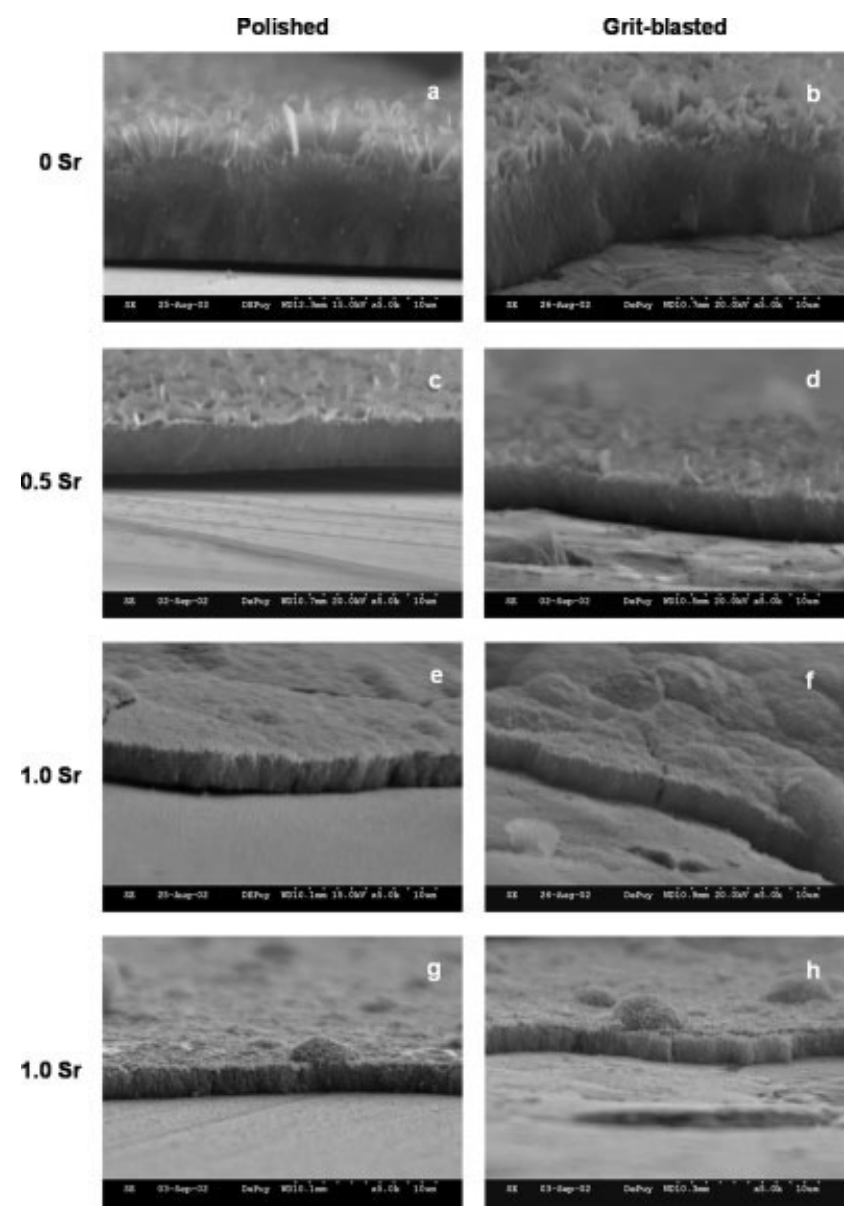

Figure 4. Morphology and thickness of the apatite layers formed on polished (a,c,e,g) and grit-blasted (b,d,f,h) surfaces after 7 days in SBF containing increasing amounts of $\mathrm{Sr}$ in solution: $(\mathrm{a}, \mathrm{b}) 0 \mathrm{mM}$, (c, d) $0.5 \mathrm{mM}$, (e, f) $1.0 \mathrm{mM}$, and $(\mathrm{g}, \mathrm{h}) 1.5 \mathrm{mM}$.

$1 \mathrm{~m} M$ of $\mathrm{Sr}$, where it is possible to identify the presence of this element. This spectrum is representative of the profiles obtained after $\mathrm{Sr}$ was incorporated at the different doses. After the coating process, the samples were washed in de-ion-

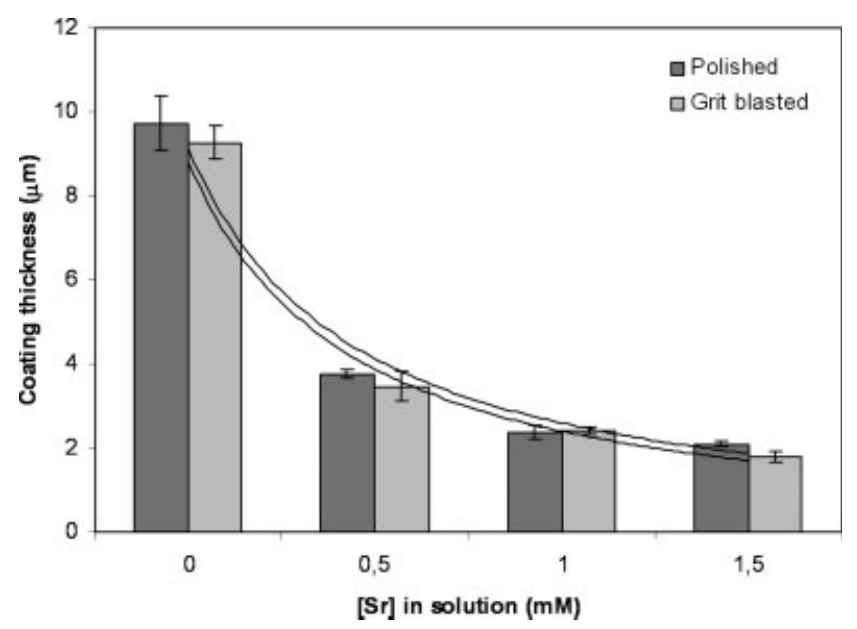

Figure 5. Average thickness of the apatite layers formed in solutions containing increasing amounts of $\mathrm{Sr}$.

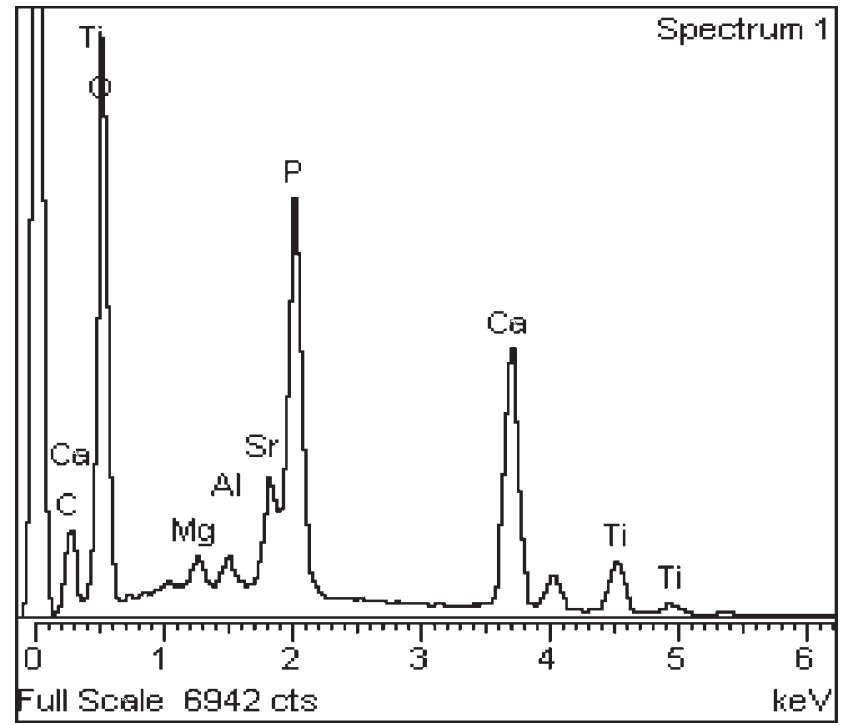

Figure 6. Typical EDS spectra obtained for the formed Sr-apatite layers after 7 days of the coating process.

ized water to remove a residue of coating source solution. The absence of $\mathrm{Na}$ or $\mathrm{Cl}$ indicates that the surface is clean. The Sr detected on the surface is the element that is chemically incorporated in the apatite structure. $\mathrm{Sr}$ was identified even when a lower amount of $\mathrm{Sr}(0.5 \mathrm{mM})$ was added to solution. Trace amounts of $\mathrm{Mg}$ were also detected together with Sr. In fact the affinity of this ion for the apatite structure increased with the presence of Sr. Titanium and Aluminum are also detected from the substrate, which is composed of a commercially available Ti alloy (Ti6Al4V).

Figure 7 presents the most important region of the DRFTIR spectra of the apatite coatings produced in the various solutions.

The bands detected at $1636 \mathrm{~cm}^{-1}$ are assigned to water molecules in the apatite structure. Another broad band assigned to water was also detected in the region of

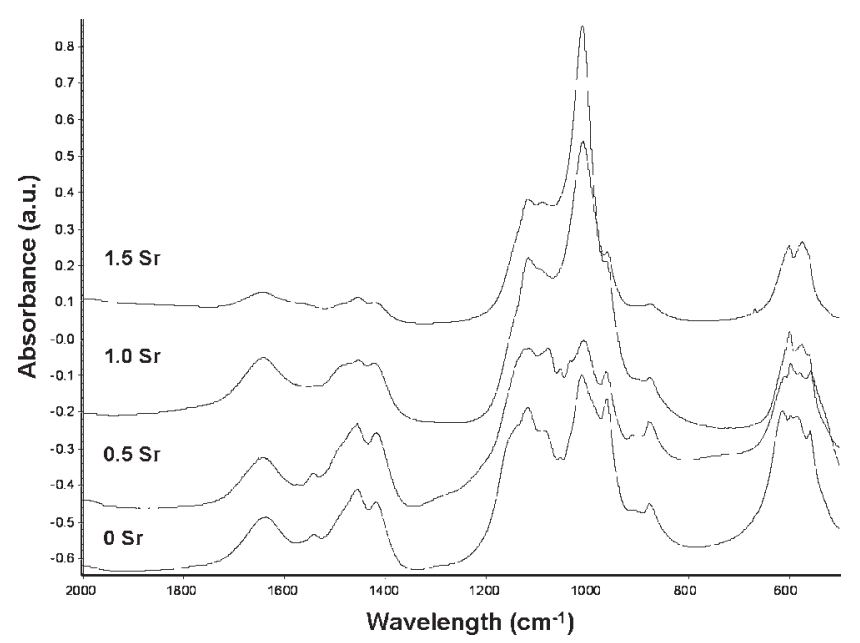

Figure 7. DR-FTIR of the apatite coatings formed in the solutions containing increasing concentrations of Sr. 


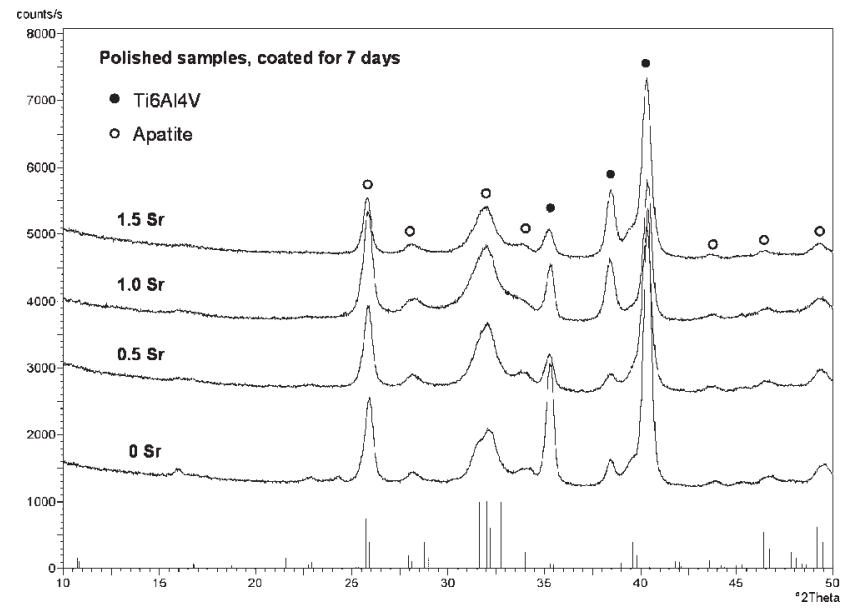

Figure 8. TF-XRD of the apatite coatings formed in the solutions containing increasing concentrations of $\mathrm{Sr}$.

$3200 \mathrm{~cm}^{-1}$ (data not shown). In fact, apatite contains water incorporated in its structure, either chemically bonded, i.e. structural water or also adsorbed because of its hydroscopic character. ${ }^{41}$ The bands at 870,1410 , and $1446 \mathrm{~cm}^{-1}$ result from the presence of carbonate $\left(\mathrm{CO}_{3}{ }^{2-}\right)$ incorporated in the apatite lattice. ${ }^{41,42}$ The presence of these bands clearly indicates that a carbonated apatite was formed, as it is found in bone apatite. The bands at 602 and 578 are assigned to the $v 4$ bending mode of the $\mathrm{O}-\mathrm{P}-\mathrm{O}$ bonds in the apatite. The bands at 1072 and $1112 \mathrm{~cm}^{-1}$ indicate the $(3$ stretching mode of $\mathrm{P}-\mathrm{O}$ bonds. ${ }^{41}$

Figure 8 presents the TF-XRD spectra of the apatite coatings with increasing $\mathrm{Sr}$ content. Figure 9 presents in detail the region of the (002) plane.

By TF-XRD (Figure 8) it was possible to identify the main characteristic peaks attributed to HA. The peak at $2 \theta=26^{\circ}$ is assigned to (002) plane in the lattice of apatite crystal. The strong diffraction intensity of this peak suggests a preferential orientation of the crystals. Another important diffraction peak is detected around $2 \theta=32^{\circ}$ and is related to the overlapping of planes (211), (112), and (300). This broad peak indicates that the apatite is poorly crystalline. When comparing in detail the apatite peaks it is possible to note a shift to the left that is progressive as function of the amount of $\mathrm{Sr}$ in the coating solution. An example of this shift is found in Figure 9, in a detailed analysis of the region correspondent to the (002) plane. This shift is a close match to the reference pattern for composition $(\mathrm{Ca})_{9} \mathrm{Sr}\left(\mathrm{PO}_{4}\right)_{6}(\mathrm{HO})_{2}$, indicating that $\mathrm{Ca}$ is being replaced by $\mathrm{Sr}$ during the coating process.

\section{DISCUSSION}

The process of apatite formation in the herein studied solution is a complex phenomenon. ${ }^{28}$ It involves a number of reactions concerning the association/dissociation of the various ions and ion groups in solution, which will be affected by interactions with the titanium substrate and with the environment to which the solution is exposed. During apatite coating formation, a concurrent drop in the concentrations of $\mathrm{Ca}, \mathrm{P}$, and $\mathrm{Sr}$ (when present) in solution is detected, together with a drop of the solutions' $\mathrm{pH}$ (data not shown). This phenomenon has been studied and reported in a previous work. ${ }^{28}$ In brief, at the initial stage of the coating processes the $\mathrm{pH}$ of the solution increases because of the release of $\mathrm{CO}_{2}$ from the dissociation of $\mathrm{HCO}_{3}{ }^{-}$ions, resulting in the generation of hydroxyl ions. This is a rather well known phenomena studied by several authors ${ }^{28,43,44}$ when using comparable supersaturated solutions. However, at a certain time point a $\mathrm{pH}$ drop is observed that is coincident with a drop in the $\mathrm{Ca}$ and $\mathrm{P}$ composition. The $\mathrm{pH}$ drop results from the dissociation of $\mathrm{HPO}_{4}{ }^{2-}$ and $\mathrm{H}_{2} \mathrm{PO}_{4}{ }^{-}$ionic groups into $\mathrm{PO}_{4}{ }^{3-}$ which will then bond to $\mathrm{Ca}^{2+}$ to the form the apatite coating.

When $\mathrm{Sr}$ is present in higher amounts in solution the $\mathrm{Ca}$ and $\mathrm{P}$ drop is delayed (as well as the correspondent $\mathrm{pH}$ drop), indicating delay in the coating formation due to an inhibitory effect of this ion. This effect was reflected in the resulting apatite layers' morphology. A decrease in the crystal size was observed when adding increasing amounts of $\mathrm{Sr}$ to the solution, indicating that its presence inhibits the growing of the apatite crystals, increasing the nanocharacter of the apatite structure. This result suggests that $\mathrm{Sr}$ can have an inhibitory effect similar to the well-known effect of $\mathrm{Mg}$, as reported by several authors. ${ }^{40,45,46} \mathrm{~A}$ pronounced inhibitory effect is observed when only $0.5 \mathrm{mM} \mathrm{Sr}$ is added to the solution, resulting in a marked decrease in the thickness of the apatite layer. When increasing the $\mathrm{Sr}$ content the thickness continues to decrease, however not in such a prominent way. Therefore, it can be said that increasing $[\mathrm{Sr}]$ in solution has a negligible effect on the coating thickness.

When comparing the FTIR spectra, the intensity of the band at $1072 \mathrm{~cm}^{-1}$ (v3 stretching mode of $\mathrm{P}-\mathrm{O}$ bonds)

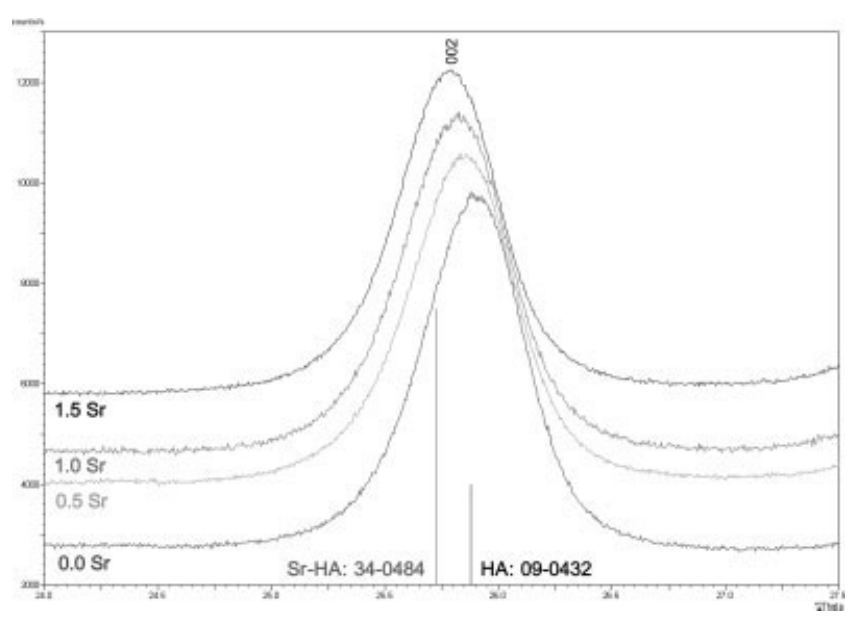

Figure 9. Detail of the XRD peaks assigned to the (002) lattice plane indicating a shift to the left on coatings formed in solutions with increasing Sr. 
increases in case of the coatings formed in solutions containing 1.0 and $1.5 \mathrm{~m} M$ of $\mathrm{Sr}$. This type of profile was also observed in the case of apatite coatings formed in the absence of $\mathrm{Sr}$ in the first days of the coating process (data not shown). The higher intensity of this band might be related to the thickness of the coating or to its overall composition. In fact, absorbance is related to the quantity of function group determined by the coating thickness. On the other hand, since the solution is not replenished during the 7 days of the experiment, the degree of solution supersaturation decreases over time, which might be affecting the composition of the apatite over time of immersion. Nevertheless, FTIR analysis neither reveals a significant shift of $\mathrm{PO}_{4}$ bands nor demonstrates addition of any other bands, indicating that these possible compositional changes are not significant.

Although FTIR analysis did not reveal any significant difference between the spectra of the Sr-free and Sr-containing apatite coatings, by TF-XRD analysis a progressive shift of the main apatite peaks was observed towards the typical composition of $\mathrm{Sr}$ substituted apatite. $\mathrm{Sr}$ atoms, although having a higher ionic radii than $\mathrm{Ca}$ are able to replace them, which will lead to a distortion in the crystal lattice and consequently to a deviation of the diffraction planes. These results qualitatively associate with the observations made of the solutions evolution during the process. The mechanism by which $\mathrm{Sr}$ is being incorporated in the apatite structure is, therefore, by the substitution of $\mathrm{Sr}$ for $\mathrm{Ca}$. Further studies, however, are required in order to determine the exact composition of these new biomimetic Srsubstituted apatite coatings.

\section{CONCLUSIONS}

In this study it was possible to incorporate different amounts of $\mathrm{Sr}$ into the structure of the apatite layer by adding $\mathrm{SrCl}_{2}$ in biomimetic apatite coating source solution. $\mathrm{Sr}$ ions are extracted from the solution to substitute for $\mathrm{Ca}$ in apatite coating during its formation, leading to the formation of a Sr-substituted apatite coating. The presence of $\mathrm{Sr}$ ions in solution could inhibit the coating formation and results in the decrease of coating thickness. The formed Srcontaining biomimetic coatings presented a bone-like structure similar to the one found in the human bone. This new Sr-apatite coatings are expected to have a positive effect in enhancing bone formation and therefore to contributing to better osteointegration.

\section{REFERENCES}

1. Grynpas MD, Marie PJ. Effects of low-doses of strontium on bone quality and quantity in rats. Bone 1990;11:313-319.

2. Marie PJ, Ammann P, Boivin G, Rey C. Mechanisms of action and therapeutic potential of strontium in bone. Calcif Tissue Int 2001;69:121-129.

3. Canalis E, Hott M, Deloffre P, Tsouderos Y, Marie PJ. The divalent strontium salt S12911 enhances bone cell replication and bone formation in vitro. Bone 1996;18:517-523.
4. Su Y, Bonnet J, Deloffre P, Tsouderos Y, Baron R. The strontium salt-S12911 inhibits the expression of carbonic-anhydrase and the vitronectin receptor in chicken bone-marrow cultures and bone-resorption in mouse calvaria and isolated rat osteoclasts. J Bone Miner Res 1992;7:S306.

5. Marie PJ. Strontium as therapy for osteoporosis. Curr Opin Pharmacol 2005;5:633-636.

6. Marie PJ, Garba MT, Hott M, Miravet L. Effect of low-doses of stable strontium on bone metabolism in rats. Miner Electrolyte Metab 1985;11:5-13.

7. Marie PJ, Hott M. Short-term effects of fluoride and strontium on bone-formation and resorption in the mouse. Metab Clin Exp 1986;35:547-551.

8. Buehler J, Chappuis P, Saffar JL, Tsouderos Y, Vignery A. Strontium ranelate inhibits bone resorption while maintaining bone formation in alveolar bone in monkeys (Macaca fascicularis). Bone 2001;29:176-179.

9. Dahl SG, Allain P, Marie PJ, Mauras Y, Boivin G, Ammann $\mathrm{P}$, Tsouderos Y, Delmas PD, Christiansen C. Incorporation and distribution of strontium in bone. Bone 2001;28:446-453.

10. Boivin G, Deloffre P, Perrat B, Panczer G, Boudeulle M, Mauras Y, Allain P, Tsouderos Y, Meunier PJ. Strontium distribution and interactions with bone mineral in monkey iliac bone after strontium salt (S 12911) administration. J Bone Miner Res 1996;11:1302-1311.

11. Christoffersen J, Christoffersen MR, Kolthoff N, Barenholdt O. Effects of strontium ions on growth and dissolution of hydroxyapatite and on bone mineral detection. Bone 1997;20: 47-54.

12. Skoryna SC. Effects of oral supplementation with stable strontium. Can Med Assoc J 1981;125:703-712.

13. Curzon MEJ, Spector PC. Strontium uptake and enamel dissolution in bovine and human-enamel. Caries Res 1983;17:249252.

14. Mccaslin FE, Janes JM. The effect of strontium lactate in the treatment of osteoporosis. Proc Staff Meet Mayo Clin 1959; 34:329-334.

15. Reginster JY, Lecart MP, Deroisy R, Lousberg C. Strontium ranelate: a new paradigm in the treatment of osteoporosis. Expert Opin Investig Drugs 2004;13:857-864.

16. Reginster JY, Deroisy R, Jupsin I. Strontium ranelate: A new paradigm in the treatment of osteoporosis. Drugs Today 2003;39:89-101.

17. Meunier PJ, Roux C, Seeman E, Ortolani S, Badurski JE, Spector TD, Cannata J, Balogh A, Lemmel EM, Pors-Nielsen S, Rizzoli R, Genant HK, Reginster JY. The effects of strontium ranelate on the risk of vertebral fracture in women with postmenopausal osteoporosis. N Engl J Med 2004;350:459468.

18. Roux C, Reginster JY, Fechtenbaum J, Kolta S, Sawicki A, Tulassay Z, Luisetto G, Padrino JM, Doyle D, Prince R, Fardellone P, Sorensen OH, Meunier PJ. Vertebral fracture risk reduction with strontium ranelate in women with postmenopausal osteoporosis is independent of baseline risk factors. J Bone Miner Res 2006;21:536-542.

19. Reginster JY, Seeman E, De Vernejoul MC, Adami S, Compston J, Phenekos C, Devogelaer JP, Curiel MD, Sawicki A, Goemaere S, Sorensen OH, Felsenberg D, Meunier PJ. Strontium ranelate reduces the risk of nonvertebral fractures in postmenopausal women with osteoporosis: Treatment of Peripheral Osteoporosis (TROPOS) Study. J Clin Endocrinol Metab 2005;90:2816-2822.

20. Degroot K, Geesink R, Klein CPAT, Serekian P. Plasma sprayed coatings of hydroxylapatite. J Biomed Mater Res 1987;21:1375-1381.

21. Jaffe WL, Scott DF. Total hip arthroplasty with hydroxyapatite-coated prostheses. J Bone Joint Surg Am A 1996;78: 1918-1934. 
22. Geesink RGT, Degroot K, Klein CPAT. Chemical implant fixation using hydroxyl-apatite coatings-The development of a human total hip-prosthesis for chemical fixation to bone using hydroxyl-apatite coatings on titanium substrates. Clin Orthop Relat Res 1987;225:147-170.

23. Li PJ, Ducheyne P. Quasi-biological apatite film induced by titanium in a simulated body fluid. J Biomed Mater Res 1998; 41:341-348.

24. Oliveira AL, Gomes ME, Malafaya PB, Reis RL. Biomimetic coating of starch based polymeric foams produced by a calcium silicate based methodology. Bioceramics 2003;240/242: 101-104.

25. Oliveira AL, Elvira C, Reis RL, Vazquez B, San Roman J. Surface modification tailors the characteristics of biomimetic coatings nucleated on starch-based polymers. J Mater Sci Mater Med 1999;10:827-835.

26. Li P, Nakanishi K, Kokubo $\mathrm{T}$, de Groot $\mathrm{K}$. Induction and morphology of hydroxyapatite, precipitated from metastable simulated body fluids on sol-gel prepared silica. Biomaterials 1993;14:963-968.

27. Kokubo T, Kushitani H, Sakka S, Kitsugi T, Yamamuro T. Solutions able to reproduce in vivo surface-structure changes in bioactive glass-ceramic A-W. J Biomed Mater Res 1990;24:721-734.

28. Li PJ. Biomimetic nano-apatite coating capable of promoting bone ingrowth. J Biomed Mater Res A 2003;66:79-85.

29. Rose FRAJ, Hou QP, Oreffo ROC. Delivery systems for bone growth factors-The new players in skeletal regeneration. J Pharm Pharmacol 2004;56:415-427.

30. Luginbuehl V, Meinel L, Merkle HP, Gander B. Localized delivery of growth factors for bone repair. Eur J Pharm Biopharm 2004;58:197-208.

31. Krout A, Wen HB, Hippensteel E, Li PJ. A hybrid coating of biomimetic apatite and osteocalcin. J Biomed Mater Res A 2005;73:377-387.

32. Rodan GA, Martin TJ. Therapeutic approaches to bone diseases. Science 2000;289:1508-1514.

33. Li P; DePuy Orthopaedics, Inc., assignee. Bioactive ceramic coating and method. USA Pat (2000) 6, 569, 489.

34. Li P; DePuy Products, Inc., assignee. Strontium-substituted apatite coating. USA Pat (2005) 6, 905, 723.

35. Morohashi T, Sano T, Yamada S. Effects of strontium on calcium-metabolism in rats. I. A distinction between the pharmacological and toxic doses. Jpn J Pharmacol 1994;64:155-162.
36. Marie PJ, Hott M, Modrowski D, Depollak C, Guillemain J, Deloffre P, Tsouderos Y. An uncoupling agent containing strontium prevents bone loss by depressing bone-resorption and maintaining bone-formation in estrogen-deficient rats. J Bone Miner Res 1993;8:607-615.

37. Marie PJ, Hott M. Short-term effects of fluoride and strontium on bone forming and bone resorbing cells in the mouse. Calcif Tissue Int 1986;38:S17.

38. Grynpas MD, Hamilton E, Cheung R, Tsouderos Y, Deloffre P, Hott M, Marie PJ. Strontium increases vertebral bone volume in rats at a low dose that does not induce detectable mineralization defect. Bone 1996;18:253-259.

39. Dick WA, Tabatabai MA. Determination of orthophosphate in aqueous-solutions containing labile organic and inorganic phosphorus-compounds. J Environ Qual 1977;6:82-85.

40. Barrere F, Layrolle P, Van Blitterswijk CA, De Groot K. Biomimetic calcium phosphate coatings on Ti6Al4V: A crystal growth study of octacalcium phosphate and inhibition by $\mathrm{Mg} 2+$ and $\mathrm{HCO}_{3}^{-}$. Bone 1999;25:107S-111S.

41. Vallet-Regi M, Romero AM, Ragel CV, LeGeros RZ. XRD, SEM-EDS, and FTIR studies of in vitro growth of an apatitelike layer on sol-gel glasses. J Biomed Mater Res 1999;44: 416-421.

42. Rehman I, Bonfield W. Characterization of hydroxyapatite and carbonated apatite by photo acoustic FTIR spectroscopy. J Mater Sci: Mater Med 1997;8:1-4.

43. Barralet J, Best S, Bonfield W. Carbonate substitution in precipitated hydroxyapatite: An investigation into the effects of reaction temperature and bicarbonate ion concentration. J Biomed Mater Res 1998;41:79-86.

44. Barrere F, van Blitterswijk CA, de Groot K, Layrolle P. Influence of ionic strength and carbonate on the Ca-P coating formation from SBFx5 solution. Biomaterials 2002;23:19211930.

45. Barrere F, van Blitterswijk CA, de Groot K, Layrolle P. Nucleation of biomimetic Ca-P coatings on Ti6Al4V from a $\mathrm{SBF} \times 5$ solution: Influence of magnesium. Biomaterials 2002;23:2211-2220.

46. Li P, Ohtsuki C, Kokubo T, Nakanishi K, Soga N, Nakamura $\mathrm{T}$, Yamamuro T. Effects of ions in aqueous media on hydroxyapatite induction by silica gel and its relevance to bioactivity of bioactive glasses and glass-ceramics. J Appl Biomater 1993;4:221-229. 